\title{
Evaluation of Surface Mount Component Misalignment Using an Automatic Machine Vision System
}

Federal Manufacturing \& Technologies

S. S. Yerganian

KCP-613-5805

Published January 1997

Final Report

Approved for public release; distribution is unlimited.

RECEVED

MAN 121997

OSTI

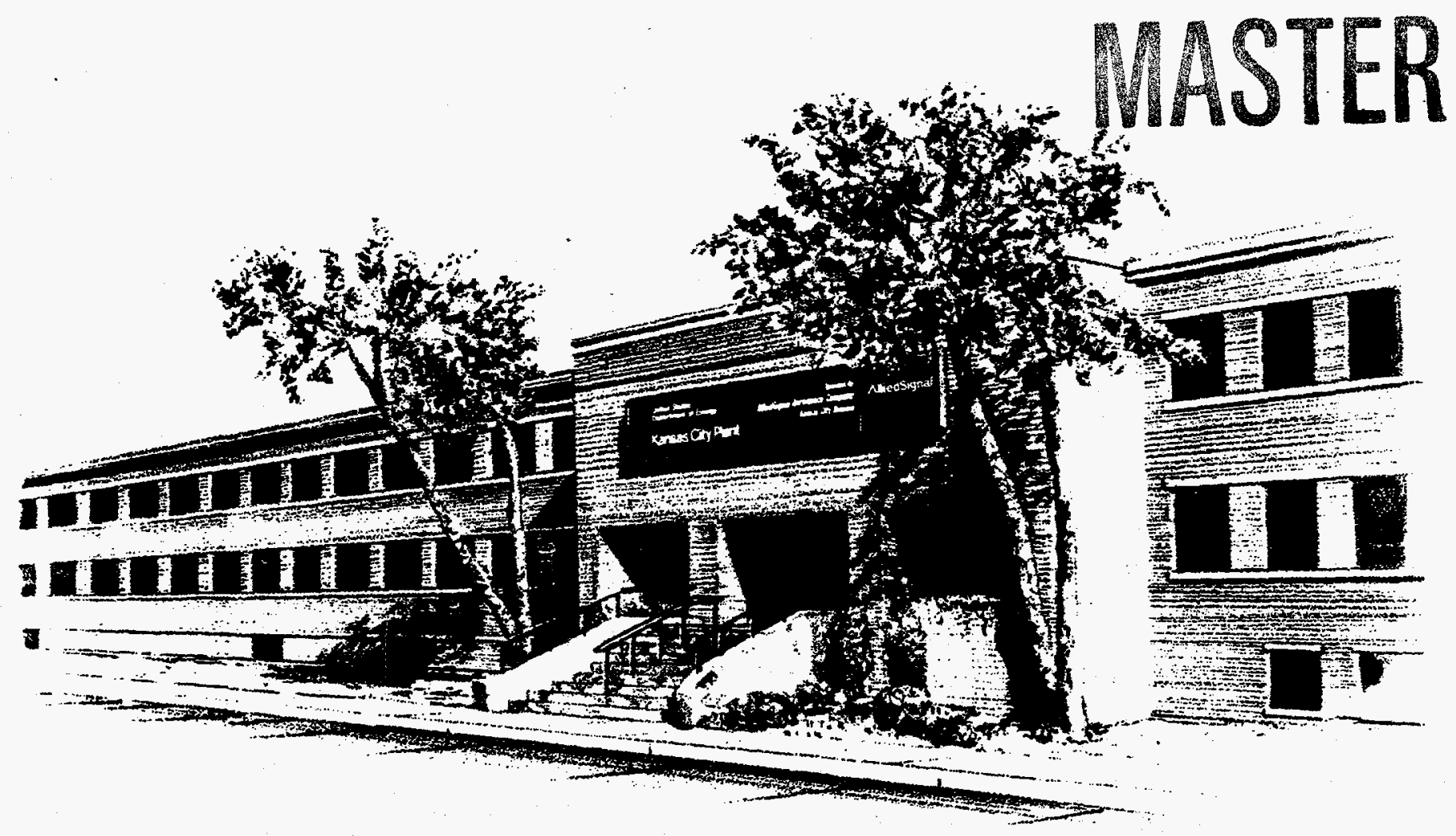

Prepared Under Contract Number DE-ACO4-76-DP00613 for the

United States Department of Energy

AlliedSignal

A E R O S P A C E 


\section{DISCLAIMER}

This report was prepared as an account of work sponsored by an agency of the United States Government. Neither the United States Government nor any agency thereof, nor any of their employees, makes any warranty, express or implied, or assumes any legal liability or responsibility for the accuracy, completeness, or usefulness of any information, apparatus, product, or process disclosed, or represents that its use would not infringe privately owned rights. The views and opinions of authors expressed herein do not necessarily state or reflect those of the United States Government or any agency thereof.

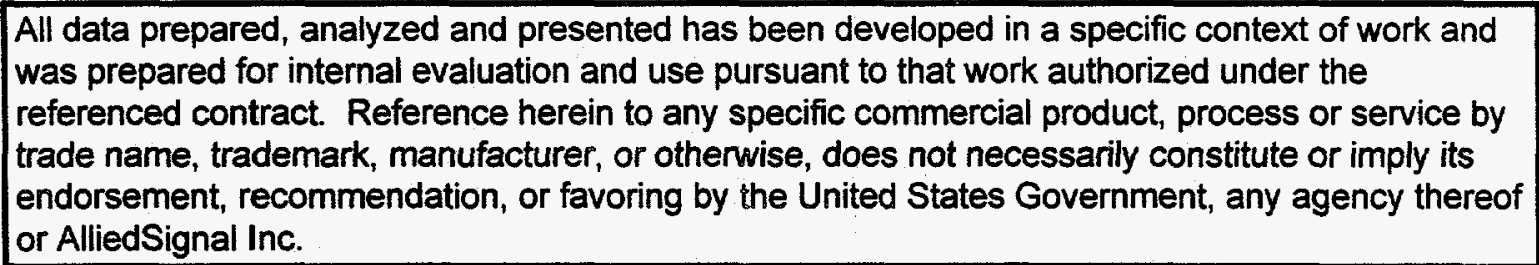

Printed in the United States of America.

This report has been reproduced from the best available copy.

Available to DOE and DOE contractors from the Office of Scientific and Technical Information, P. O. Box 62, Oak Ridge, Tennessee 37831; prices available from (615) 576-8401, FTS 626-8401.

Available to the public from the National Technical Information Service, U. S. Department of Commerce, 5285 Port Royal Rd., Springfield, Virginia 22161.

A prime contractor with the United States Department of Energy under Contract Number DE-AC04-76-DP00613.
AlliedSignal Inc. Federal Manufacturing \& Technologies P. O. Box 419159 Kansas City, Missouri 64141-6159 


\section{DISCLAIMER}

This report was prepared as an account of work sponsored by an agency of the United States Government. Neither the United States Government nor any agency thereof, nor any of their employees, make any warranty, express or implied, or assumes any legal liability or responsibility for the accuracy, completeness, or usefulness of any information, apparatus, product, or process disclosed, or represents that its use would not infringe privately owned rights. Reference herein to any specific commercial product, process, or service by trade name, trademark, manufacturer, or otherwise does not necessarily constitute or imply its endorsement, recommendation, or favoring by the United States Government or any agency thereof. The views and opinions of authors expressed herein do not necessarily state or reflect those of the United States Government or any agency thereof. 


\section{DISCLAMERR}

Portions of this document may be illegible in electronic image products. Images are produced from the best available original document. 
KCP-613-5805

Distribution Category UC-706

Approved for public release; distribution is unlimited.

\section{EVALUATION OF SURFACE MOUNT}

COMPONENT MISALIGNMENT USING AN

AUTOMATIC MACHINE VISION SYSTEM

S. S. Yerganian

Published January 1997

Final Report

S. S. Yerganian, Project Leader 


\section{CONTENTS}

$\begin{array}{lll}\text { Section Page } & \text { Pan }\end{array}$

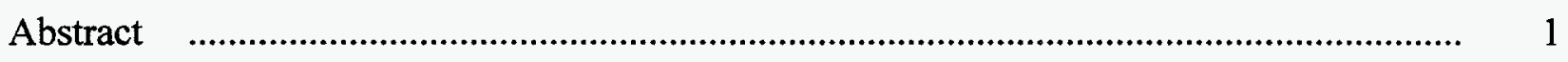

Summary

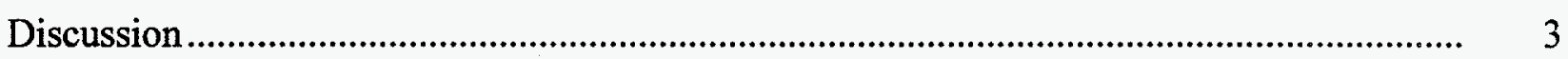

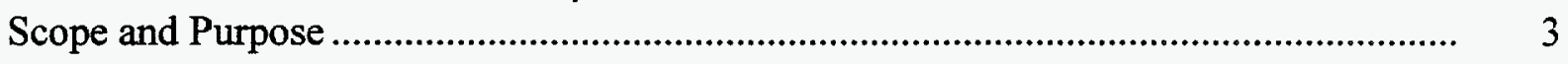

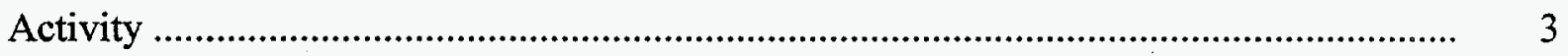

Theory of Operation...............................................................................................

System Software and Gauging Algorithms................................................................

Method for Evaluating the Three-Dimensional System's Ability to Detect

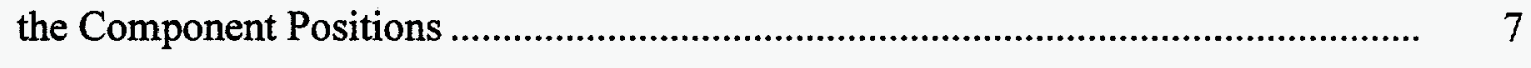

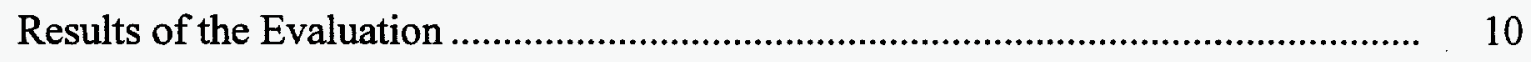

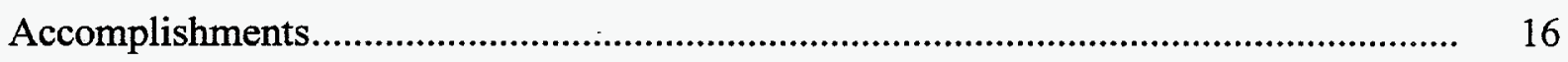




\section{ILLUSTRATIONS}

Figure

Page

1 Synthetic Vision Systems Laser-Imaging SMT Inspection System ...................... 4

2 Three-Dimensional System Operation........................................................... 5

3 Solder Fillets on Chip-Type Components ...................................................... 6

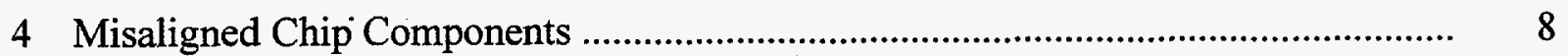

\section{TABLES}

Number

Page

1 Postsolder Inspection of First Circuit Board

2 Postsolder Inspection of Second Circuit Board

3 Presolder Inspection of Third Circuit Board

4 Presolder Inspection of Fourth Circuit Board

5 Presolder and Postsolder Inspection of Angles...

6 Inspection of RF Transistors Using SMTGauge

13

7 Evaluation of Data From Tables 1 Through 6 


\begin{abstract}
A system manufactured by Synthetic Vision Systems Inc. was evaluated for its ability to automatically inspect surface mount components on a densely populated printed wiring board assembly for component presence and proper alignment before and after soldering. The system was evaluated for its use as a process verification tool in the presoldered mode and as a supplement to visual inspection in the postsoldered mode. To test the ability of the three-dimensional imaging system to locate the component edges in both the presoldered and postsoldered cases, data was gathered by inspecting four printed wiring board assemblies with the system.
\end{abstract}

\title{
SUMMARY
}

A system was characterized for its ability to automatically inspect surface mount components on densely populated printed wiring boards for component presence and for proper alignment before and after soldering. The system was evaluated for its use as a process verification tool in the presoldered mode and as a supplement to visual inspection in the postsoldered mode.

The system evaluated was a model 6800 inspection system from Synthetic Vision Systems Inc. The system uses a laser light source which is projected onto the circuit and reflects back into a detector. It can function as either a two- or three-dimensional 256 gray level imaging system. The system includes various operator-controlled gauging algorithms for inspection.

An evaluation of the system accuracy was made using the more accurate three-dimensional mode, with the most accurate gauging algorithm. This evaluation was performed by inspecting four printed wiring boards and comparing the system inspection data with measurements made by the Precision Measurement department at Federal Manufacturing \& Technologies (FM\&T) using a measuring microscope.

The system was programmed to inspect chip resistors, chip capacitors, and RF transistors. Plastic molded inductors could not be imaged because the body of the inductors absorbed the laser light. A special technique was developed for inspecting the RF transistors using a gauging algorithm originally designed for the chip components. Another special technique was developed for working with the solder-tinned tabs at the top of the circuit assembly which were used as fiducial marks.

The majority of data was collected for the smallest chip resistor because it is the most common part used on the circuit and the most difficult to image. Problems in imaging this resistor were created by the solder joints. The solder in these joints typically exceeded the desirable amount, due to variation in the printed wiring boards and to silk screening application techniques used in 1987 when these assemblies were made. 
After the evaluation was performed, it was determined that the system was more accurate at finding the center of the component than a typical visual inspection without the use of a measuring microscope. The system was very unlikely to allow misaligned components to pass as good, but the difficulties with "fat" solder terminations caused a fair number of false rejects per inspection. This results in a system that narrows down the number of components that need to be evaluated but does not replace human visual inspection. Newer systems such as those made by Robotic Vision Systems include capabilities for both misalignment inspection and solder joint inspection. 


\section{DISCUSSION}

\section{SCOPE AND PURPOSE}

This purpose of this project was to characterize the ability to automatically detect missing and misaligned surface mount components for a very densely populated printed wiring board assembly. The density and large number of components on this board make it difficult for both the operator and inspector to find all missing components, misaligned components, and solder defects. The system was evaluated for its ability to automatically inspect for missing or misaligned components. It has no capabilities to perform inspection of solder joints.

\section{ACTIVITY}

The use of a three-dimensional automated visual inspection system was investigated for its ability to inspect the position of components placed on polyimide quartz printed wiring boards. The system evaluated was a model 6800 inspection system from Synthetic Vision Systems Inc. The system as shown in Figure 1 was used to inspect the board before and after the solder was reflowed to form the solder joints. These two inspections are referred to as the presolder and postsolder cases, respectively. To evaluate the system's inspection performance, its inspection

- results were compared with the location data of components placed on two presoldered and two postsoldered boards supplied by the Precision Measurement department at FM\&T.

\section{Theory of Operation}

The system uses a laser light source which is projected onto the circuit and reflects back into a detector. It can function as either a two- or three-dimensional 256 gray level imaging system. The video image consists of a matrix of 480 by 512 pixels, with each pixel given a shade of gray color ranging from 0 (black) to 255 (white).

The two-dimensional system acts similar to any other 256 gray scale vision system by detecting the edges of components based on the contrast between the shade of the component and its background. Depth is perceived by closer objects appearing light and farther objects appearing dark.

The three-dimensional system detects the edges of components by a sudden shift in height of the surface which reflects the laser light back into the detector. The detector recognizes this height shift by the change in the position in which the reflected laser light strikes it (Figure 2). The three-dimensional system eliminates the problems that the two-dimensional system has in detecting component edges whenever there is not enough contrast between the component and background. In the postsolder inspection of a circuit, the slope at the edge of a component along 


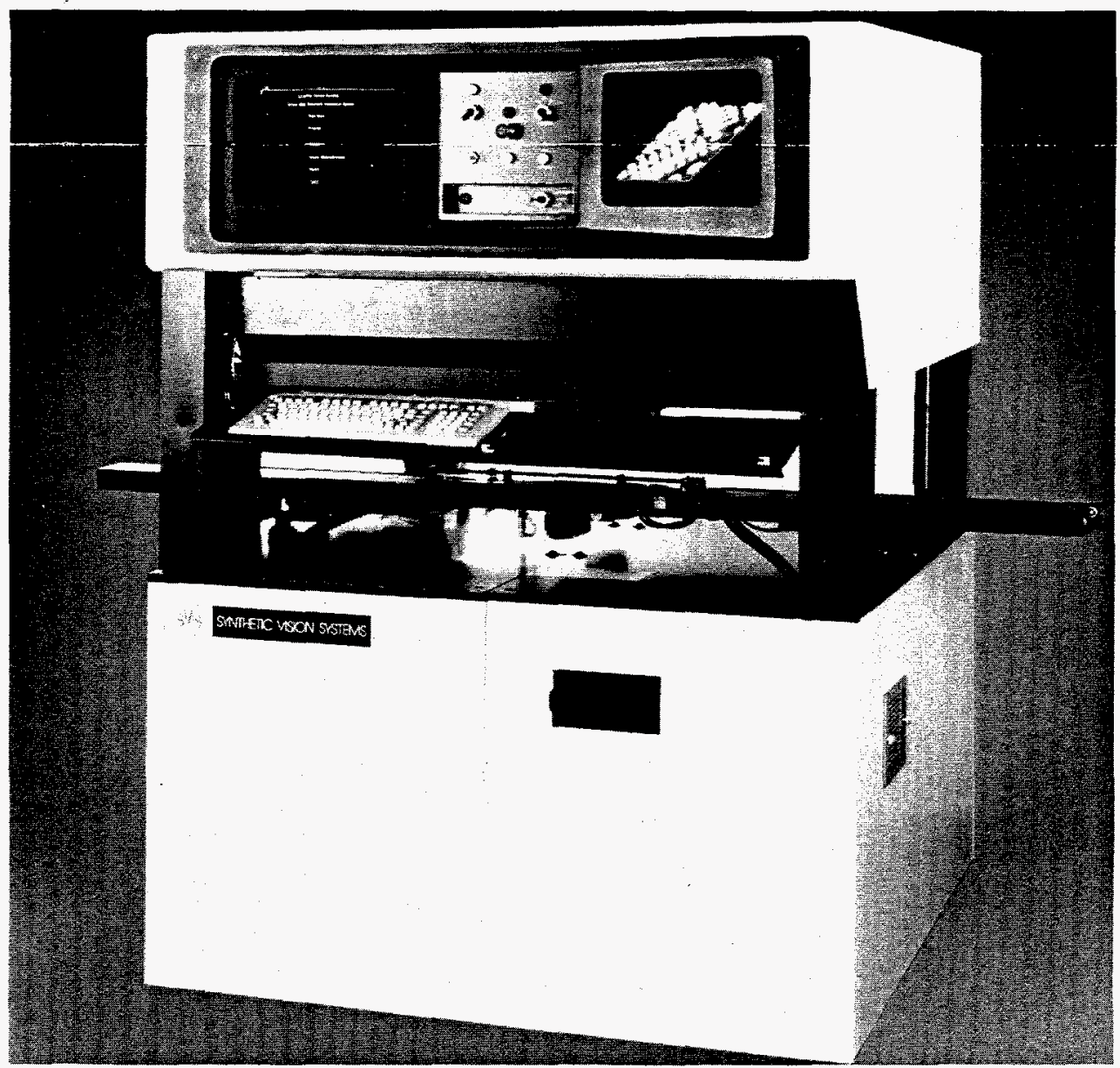

Figure 1. Synthetic Vision Systems Laser-Imaging SMT Inspection System

a termination is determined by the geometry of the reflowed solder joint. Since the threedimensional system recognizes a component edge from a sudden shift in reflected light position on the detector, a component edge defined by a gradual sloping solder fillet is difficult for the system to detect. Solder fillets creating difficulty for edge detection by the system are similar to the maximum acceptable illustration from the A issue of the soldering specification SS394234 shown in Figure 3.

\section{System Software and Gauging_Algorithms}

To define the inspection used for a particular component position on a circuit, the expected position, component geometry, and method for inspection are specified. The geometry, rotational orientation, and method of inspection for a particular component size are defined as a "template." The position coordinates, circuit reference for naming that particular position, and template to be used at this location are stored in the information defined as the "device" data. To define the method for inspecting a component, a gauging algorithm is chosen and specified within a template. 


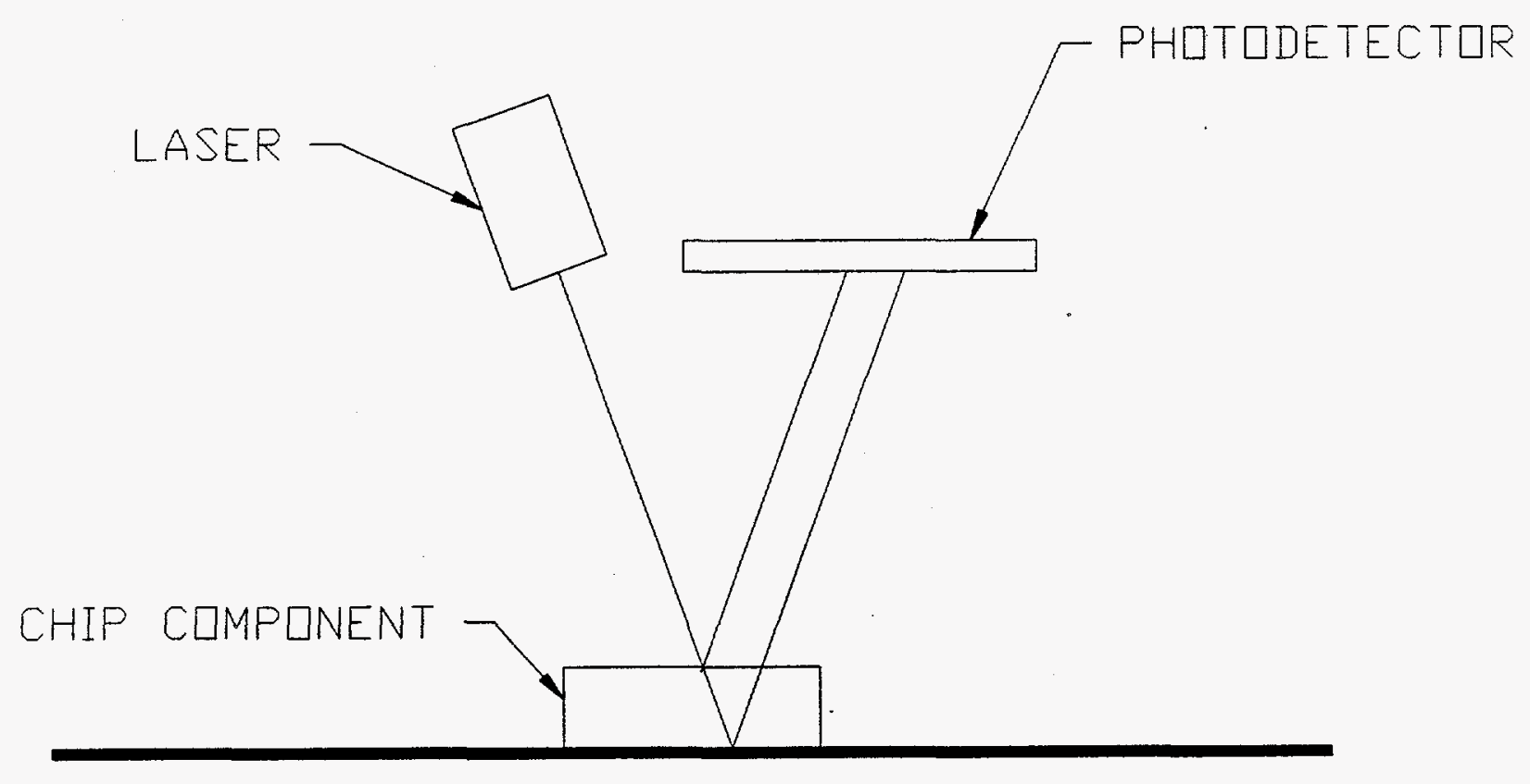

Figure 2. Three-Dimensional System Operation

Once the system has determined the component edges, it calculates the center of the component and compares this value to that tolerance band specified by the user. The user supplies tolerance criteria for the misalignment, which the system should flag as an "alarm" (barely within tolerance but outside of desired control limits), and for the out-of-tolerance criteria for misalignment, which the system flags as a "fault.". Following is a listing and explanation of the various gauging algorithms:

- XYGauge -- This algorithm determines the position and rotation of the component by finding the four lines that best describe the edges of the component sides. The edges can be found by using either the two- or three-dimensional imaging systems. This gauging algorithm then calculates the centroid of the component and compares its position with the expected position programmed for that location. To define a template using this gauging algorithm, an inspection box is assigned for each side of the component, with the boxes designated as north, south, east, or west. One of the boxes is specified to evaluate the rotation of the component. This is performed by determining the angle within the box of the line found to describe the component edge.

- XYTGauge -- This uses the same algorithm as XYGauge but with the addition of a fifth box designated as theta for the determination of the rotation of the component. 


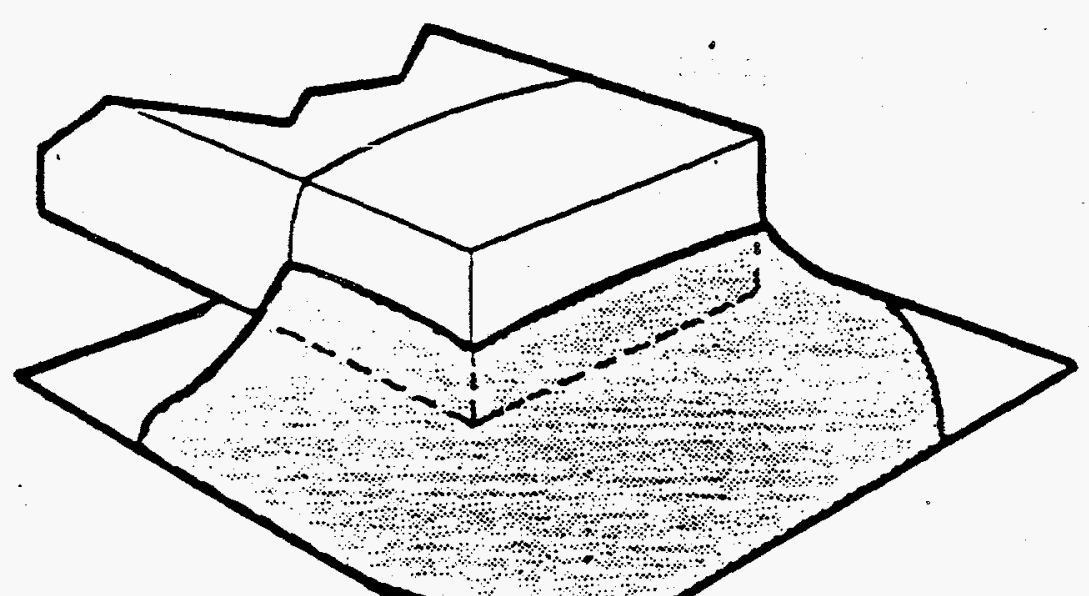

SS394234

Issue A

Page 17

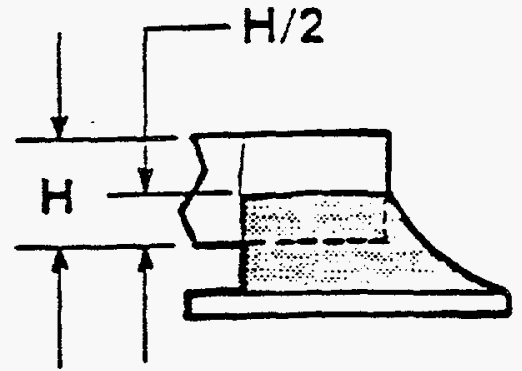

PREFERRED
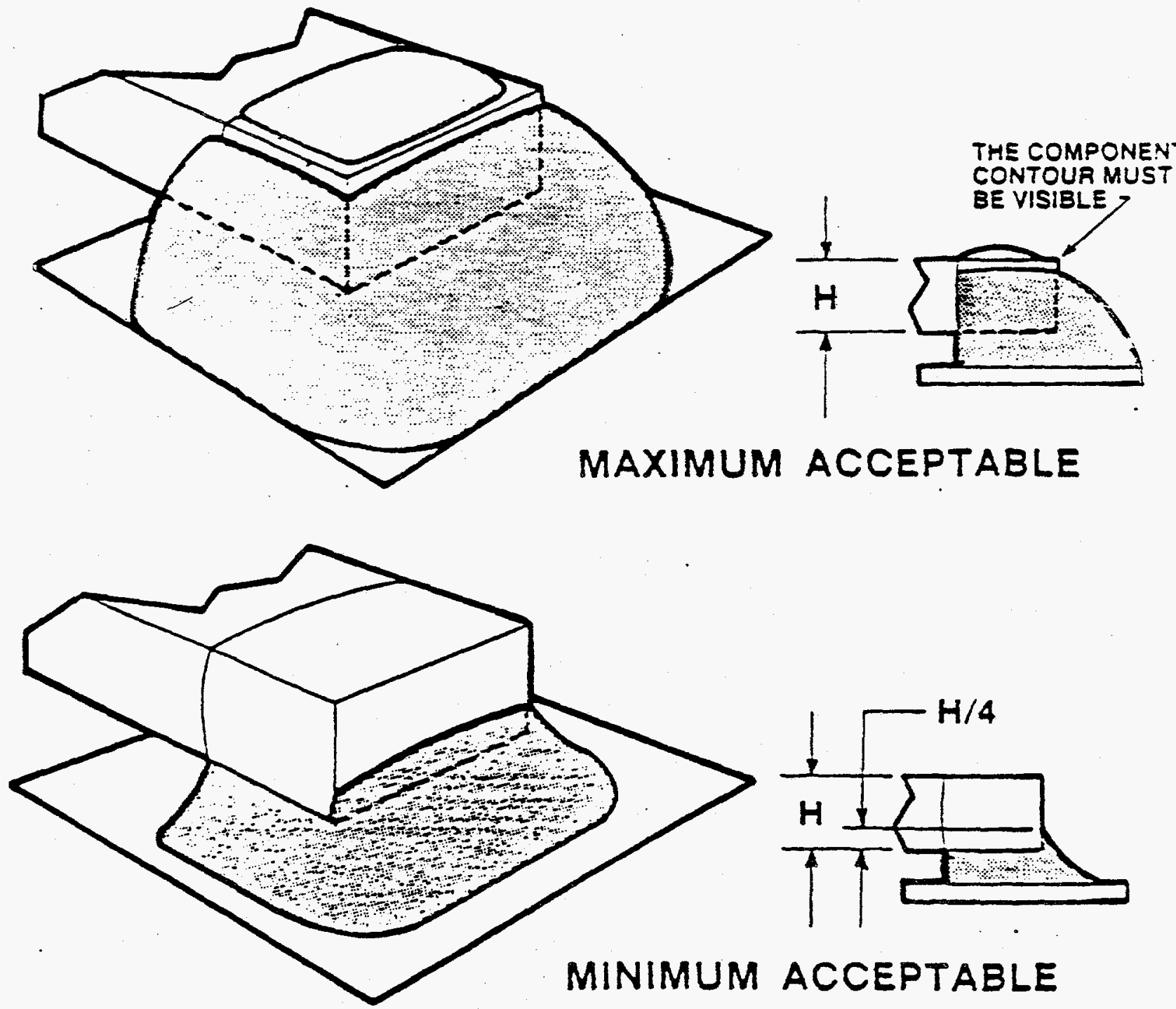

Figure 3. Solder Fillets on Chip-Type Components 
- VHGauge -- This algorithm is similar to XYGauge with the exception that only two boxes are used (one horizontal and one vertical). It trades accuracy for a reduction in processing time.

- VHTGauge -- This uses the same algorithm as the VHGauge, with the addition of a third box used to determine the rotation of the component.

- Position -- This algorithm differs from the others in that it does not use edge detection to determine component position. With this algorithm, the size and position of a box are programmed over the expected location of a component. The system then measures the area of any object within this box that is taller than a programmed height which represents a small distance above the board surface: With the two-dimensional imaging system, brightness in the reflected light is equated to height. In the three-dimensional system, the height is determined by the position in which light strikes the detector. This algorithm is the least accurate but greatly shortens the processing time because it does not calculate the position of any edges. It determines the position of the center of the component as the centroid of the area detected.

- Tombstone - This is the same algorithm as Position, with the addition of a calculation to compare if one side of the area around the component termination is significantly higher than the area around the other termination. This is used to determine if the component has experienced a "tombstone" condition in which one termination of the component has raised up off the solder pad.

- SMGauge - This algorithm was specifically developed to detect the edges of small surface mount chip components and evaluate how well the components fit on their surface mount pads. This algorithm was developed in accordance to the A issue of soldering specification SS394234 (Figure 4). The surface mount pad geometry and criteria shown in Figure 4 as $0.25 \mathrm{~W}$ maximum and 0.005 inch minimum are programmable values that can be altered as changes are made to the circuit or specification, respectively. The SMGauge algorithm is the most accurate method of determining the position and rotational orientation of a small component and requires the most processing time of any algorithm due to the amount of data processed in the determination of the component position. Either the two- or threedimensional imaging system is used to detect the four component edges within a single inspection box placed over the expected position of the component.

\section{Method for Evaluating the Three-Dimensional System's Ability to Detect the Component Positions}

A comparison of images generated by both the two-dimensional and three-dimensional systems confirmed the assumption that three-dimensional imaging provides a more accurate representation of the component edges. Using two-dimensional imaging, a combination of glare from the shiny solder surface and dark resistive material on chip resistors lead to the false 
SS394234

Is sue $A$

Page 21

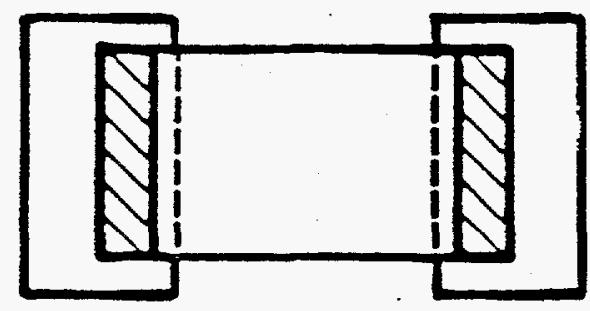

Preferred
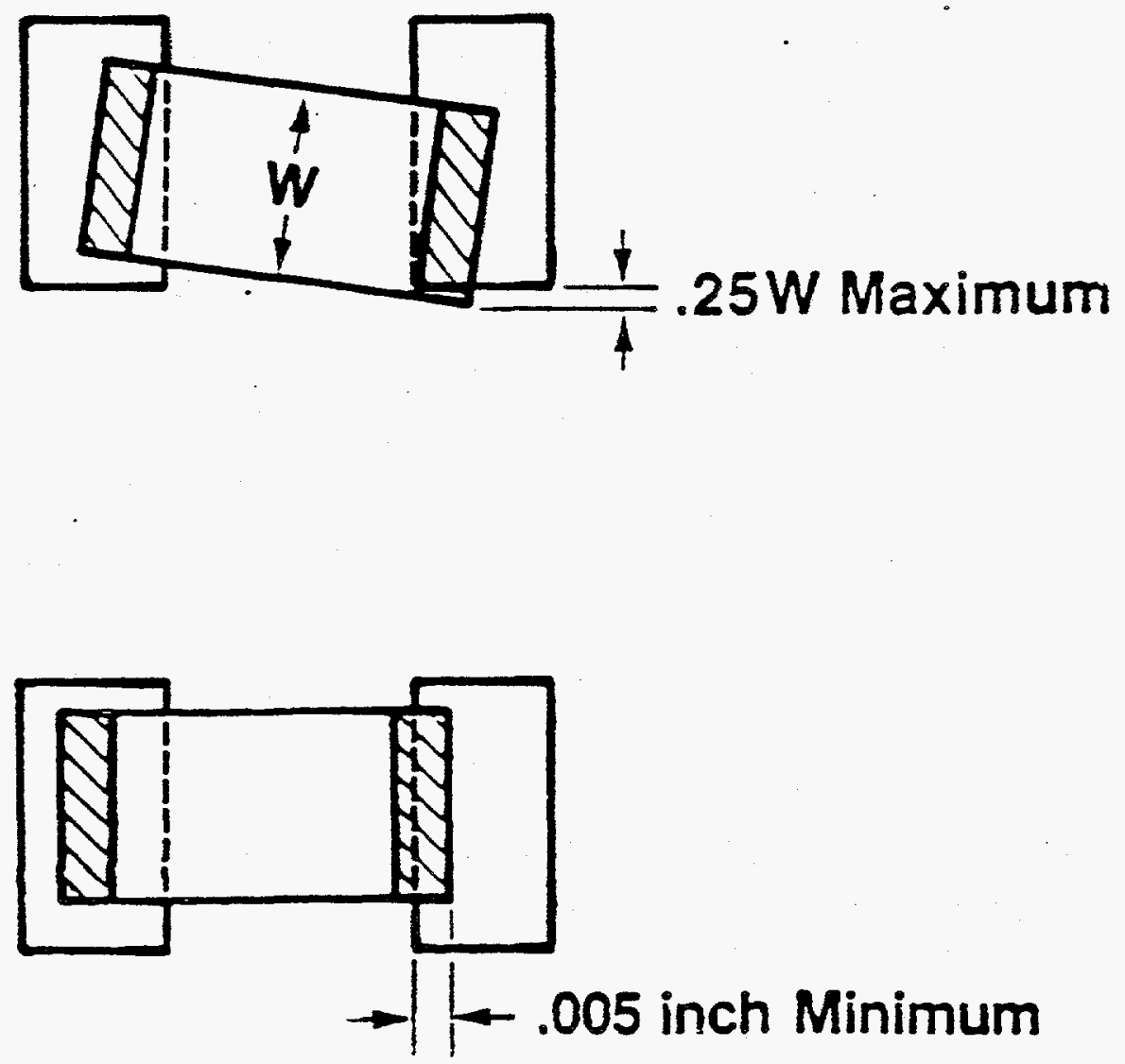

Figure 4. Misaligned Chip Components 
determination of the component edges. Although the system labels defects such as missing components, improperly positioned or oriented components, or the presence of a component of the wrong size, the determination of these defects is based solely on the ability of the system to accurately locate the edges of the component.

To test the ability of the three-dimensional imaging system to locate the component edges in both the presoldered and postsoldered cases, data was gathered by inspecting four densely populated printed wiring board assemblies with the system. Two of the boards were reflowed. The other two boards used for the presoldered inspections contained components held in place by a small drop of epoxy underneath them.

The $\mathrm{X}$ and $\mathrm{Y}$ coordinate data to the center of a number of components was collected for the two presoldered and two postsoldered printed wiring boards. These coordinates were determined by averaging the $\mathrm{X}$ and $\mathrm{Y}$ coordinates found for the four corners of each component. The coordinates of the corners of the components were measured with a Zeiss Optic measuring microscope in the Precision Measurement department at FM\&T.

All four corners of the component were used and averaged to calculate the best value for the coordinates of the component center and the rotational angle of the component. The discrepancy was then determined between this coordinate data and the data generated by the inspection of these boards by the system. This "discrepancy" is defined as the value for the component center, or rotational angle of the component found by the system minus the value calculated using the coordinates found by Precision Measurement. The results of this evaluation are in Tables 1 through 6 . The component types were as listed below:

- 550 Resistor -- Surface mount chip resistor with dimensions $0.055 \times 0.050 \times 0.020$ inch

- 5100 Resistor -- Surface mount chip resistor with dimensions $0.100 \times 0.050 \times 0.020$ inch

- 1100 Resistor -- Surface mount chip resistor with dimensions $0.110 \times 0.100 \times 0.020$ inch

- 1225 Resistor -- Surface mount chip resistor with dimensions $0.250 \times 0.125 \times 0.020$ inch

- 0805 Capacitor -- Surface mount chip capacitor with dimensions $0.080 \times 0.050 \times 0.050$ inch

- 1210 Capacitor -- Surface mount chip capacitor with dimensions $0.120 \times 0.100 \times 0.060$ inch

- 2225 Capacitor -- Surface mount chip capacitor with dimensions $0.250 \times 0.200 \times 0.070$ inch

- RF Transistor -- Surface mount transistor with dimensions $0.100 \times 0.100 \times 0.050$ inch

All component locations (including the RF transistors) were measured using the SMGauge algorithm with the exception of the 2225 capacitors which were measured using the XYTGauge algorithm (2225 capacitors are too large for the SMGauge algorithm). 
Table 1. Postsolder Inspection of First Circuit Board

\begin{tabular}{|c|c|c|c|c|c|}
\hline Position Number & Circuit Position & $\begin{array}{c}\text { Discrepancy in X } \\
\text { (mils) }\end{array}$ & $\begin{array}{c}\text { Discrepancy in Y } \\
\text { (mils) }\end{array}$ & $\begin{array}{c}\text { Component } \\
\text { Type }\end{array}$ & Observations \\
\hline 1 & CL348 & -3 & -5 & 1210 Capacitor & \\
\hline 2 & CL339 & 4 & -10 & 2225 Capacitor & 1 \\
\hline 3 & RL484 & 2 & -6 & 550 Resistor & 2 \\
\hline 4 & RL430 & -1 & 0 & 5100 Resistor & \\
\hline 5 & RL395 & -2 & -2 & 550 Resistor & \\
\hline 6 & RL450 & No X Value Found & -9 & 1100 Resistor & $2,4,7$ \\
\hline 7 & RL489 & 0 & -6 & 550 Resistor & $2,4,7$ \\
\hline 8 & CL351 & 1 & -24 & 0805 Capacitor & 3,7 \\
\hline 9 & RL355 & -7 & -7 & 5100 Resistor & $2,4,7$ \\
\hline 10 & RL389 & 0 & -1 & 550 Resistor & \\
\hline 11 & RL497 & -1 & -4 & 550 Resistor & \\
\hline 12 & RL420 & 13 & -5 & 1100 Resistor & 3,5 \\
\hline 13 & RL345 & -1 & -7 & 550 Resistor & 4,6 \\
\hline 14 & RL308 & 2 & -4 & 550 Resistor & \\
\hline 15 & CL354 & 2 & -2 & 1210 Capacitor & \\
\hline 16 & RL306 & 4 & -2 & 1100 Resistor & \\
\hline 17 & CL373 & 5 & -4 & 0805 Capacitor & \\
\hline 18 & RL412 & 8 & -7 & 550 Resistor & 2 \\
\hline 19 & RL509 & 8 & No Y Value Found & 550 Resistor & 8 \\
\hline 20 & RL448 & -17 & -6 & 550 Resistor & 8 \\
\hline
\end{tabular}

Key to Observations:

1. Large capacitor with less accuracy in both midpoint calculation and placement required

2. Component with large rotation

3. Large offset in $\mathrm{X}$ direction

4. Large offset in $\mathrm{Y}$ direction

5. System underestimating error in $X$ direction

6. System underestimating error in $\mathrm{Y}$ direction

7. System overestimating error in $Y$ direction

8. Excess solder (no clear edge)

\section{Results of the Evaluation}

The evaluation of the system demonstrated the following:

- Difficulties in detecting the fiducial marks on the circuit board

- Difficulties imaging plastic molded chip inductors

- Difficulties in edge determination of RF Transistors

- Difficulties in edge determination of chip resistors with "fat" solder terminations

- The accuracy of the system in both the presoldered and postsoldered cases 
Table 2. Postsolder Inspection of Second Circuit Board

\begin{tabular}{|c|c|c|c|c|c|}
\hline Position Number & $\begin{array}{c}\text { Circuit } \\
\text { Position }\end{array}$ & $\begin{array}{c}\text { Discrepancy in X } \\
\text { (mils) }\end{array}$ & $\begin{array}{c}\text { Discrepancy in Y } \\
\text { (mils) }\end{array}$ & Component Type & Observations \\
\hline 1 & CL339 & -2 & -6 & 2225 Capacitor & 1 \\
\hline 2 & CL368 & -2 & -9 & 2225 Capacitor & 1 \\
\hline 3 & RL435 & -3 & 0 & 550 Resistor & \\
\hline 4 & RL313 & -1 & -1 & 550 Resistor & \\
\hline 5 & RL311 & 1 & -3 & 550 Resistor & \\
\hline 6 & CL387 & -1 & -9 & 0805 Capacitor & 2,7 \\
\hline 7 & RL361 & No X Value Found & -6 & 5100 Resistor & 2,7 \\
\hline 8 & CL316 & 0 & -10 & 1210 Capacitor & 4,6 \\
\hline 9 & RL350 & 3 & -9 & 550 Resistor & 4,6 \\
\hline 10 & RL489 & 3 & -3 & 550 Resistor & \\
\hline 11 & RL426 & No X Value Found & -5 & 1100 Resistor & 2 \\
\hline 12 & RL377 & 1 & -1 & 1225 Resistor & \\
\hline 13 & RL329 & 2 & -2 & 550 Resistor & \\
\hline 14 & RL424 & 1 & -1 & 550 Resistor & \\
\hline 15 & CL333 & 0 & -3 & 2225 Capacitor & \\
\hline 16 & RL390 & -1 & 0 & 550 Resistor & \\
\hline 17 & CL322 & No X Value Found & No Y Value Found & 0805 Capacitor & 3,4 \\
\hline 18 & CL357 & 7 & -7 & 2225 Capacitor & 1 \\
\hline 19 & CL305 & 4 & -4 & 1210 Capacitor & \\
\hline 20 & RL454 & 7 & -2 & 550 Resistor & $3,4,5$ \\
\hline 21 & CL352 & 7 & No Y Value Found & 0805 Capacitor & 3,4 \\
\hline 22 & RL460 & No X Value Found & -6 & 550 Resistor & 3 \\
\hline 23 & RL462 & 8 & -6 & 550 Resistor & 3,5 \\
\hline 24 & CL386 & 7 & -9 & 0805 Capacitor & 4,7 \\
\hline
\end{tabular}

Key to Observations:

1. Large capacitor with less accuracy in both midpoint calculation and placement required

2. Component with large rotation

3. Large offset in $X$ direction

4. Large offset in $Y$ direction

5. System underestimating error in $X$ direction

6. System underestimating error in $Y$ direction

7. System overestimating error in $Y$ direction

8. Excess solder (no clear edge)

Difficulties in detecting the fiducial marks on the circuit board -- The solder-tinned tabs at the top of the board were used as fiducials. The system has the most difficulty in determining the position of a south edge using both the two- and three-dimensional imaging systems due to the direction of the light source. The reflection of the light from the board along the south end eliminated the strong contrast needed to confidently choose the edge using the two-dimensional system. The thinness of the tab made it difficult for the system to determine the shift in height necessary to find the edge using the three-dimensional system. 
Table 3. Presolder Inspection of Third Circuit Board

\begin{tabular}{|c|c|c|c|c|}
\hline Position Number & Circuit Position & $\begin{array}{c}\text { Discrepancy in X } \\
\text { (mils) }\end{array}$ & $\begin{array}{c}\text { Discrepancy in Y } \\
\text { (mils) }\end{array}$ & Component Type \\
\hline 1 & CL367 & -1 & -3 & 2225 Capacitor \\
\hline 2 & CL368 & -2 & -4 & 2225 Capacitor \\
\hline 3 & CL348 & -2 & -2 & 1210 Capacitor \\
\hline 4 & CL339 & -1 & -3 & 2225 Capacitor \\
\hline 5 & CL349 & 1 & -4 & 2225 Capacitor \\
\hline 6 & CL369 & -1 & -2 & 2225 Capacitor \\
\hline 7 & RL491 & 0 & -1 & 550 Resistor \\
\hline 8 & RL446 & 4 & -1 & 550 Resistor \\
\hline 9 & RL321 & 4 & -2 & 550 Resistor \\
\hline 10 & RL320 & -1 & -2 & 550 Resistor \\
\hline 11 & RL369 & -2 & -3 & 5100 Resistor \\
\hline 12 & RL378 & 3 & -4 & 550 Resistor \\
\hline 13 & RL499 & 3 & -3 & 550 Resistor \\
\hline 14 & RL497 & 3 & -1 & 550 Resistor \\
\hline 15 & CL357 & -1 & -4 & 2225 Capacitor \\
\hline 16 & RL509 & -1 & 2 & 550 Resistor \\
\hline 17 & RL462 & 1 & 1 & 550 Resistor \\
\hline 18 & RL460 & 0 & 5 & 550 Resistor \\
\hline 19 & CL375 & 1 & -1 & 0805 Capacitor \\
\hline
\end{tabular}

Table 4. Presolder Inspection of Fourth Circuit Board

\begin{tabular}{|c|c|c|c|c|}
\hline Position Number & Circuit Position & $\begin{array}{c}\text { Discrepancy in X } \\
\text { (mils) }\end{array}$ & $\begin{array}{c}\text { Discrepancy in Y } \\
\text { (mils) }\end{array}$ & Component Type \\
\hline 1 & RL435 & 2 & -1 & 550 Resistor \\
\hline 2 & RL331 & 1 & -2 & 550 Resistor \\
\hline 3 & RL332 & 3 & -1 & 550 Resistor \\
\hline 4 & RL488 & -1 & -1 & 550 Resistor \\
\hline 5 & RL359 & -1 & -1 & 5100 Resistor \\
\hline 6 & RL347 & -1 & -1 & 5100 Resistor \\
\hline 7 & RL426 & 1 & 0 & 1100 Resistor \\
\hline 8 & CL327 & 3 & -4 & 0805 Capacitor \\
\hline 9 & CL397 & -7 & 0 & 1210 Capacitor \\
\hline 10 & RL369 & -1 & 0 & 5100 Resistor \\
\hline 11 & CL361 & -2 & -6 & 2225 Capacitor \\
\hline 12 & RL479 & 0 & 2 & 550 Resistor \\
\hline
\end{tabular}

The other edges of the tabs were easily determined using the three-dimensional system. To eliminate the problems in detecting the fiducial marks, the north edge was defined as both the north and south edge of the fiducial mark. This created four strong edges to define the fiducial mark. The coordinates were then offset by half the length of the tab to correct for the difference in defining the fiducial this way. 
Table 5. Presolder and Postsolder Inspection of Añgles

\begin{tabular}{|c|c|c|c|c|}
\hline Board Number & $\begin{array}{c}\text { Position } \\
\text { Number }\end{array}$ & $\begin{array}{c}\text { Circuit } \\
\text { Position }\end{array}$ & $\begin{array}{c}\text { Presolder or } \\
\text { Postsolder } \\
\text { Condition }\end{array}$ & $\begin{array}{c}\text { Discrepancy of } \\
\text { Theta Angle } \\
\text { (degrees) }\end{array}$ \\
\hline 1 & 2 & CL339 & Postsolder & -5.76 \\
\hline 1 & 3 & RL484 & Postsolder & -5.58 \\
\hline 1 & 18 & RL412 & Postsolder & -6.64 \\
\hline \multicolumn{5}{|l|}{} \\
\hline 2 & 1 & CL339 & Postsolder & -0.97 \\
\hline 2 & 11 & RL426 & Postsolder & 0.6 \\
\hline 2 & 18 & CL357 & Postsolder & -7.35 \\
\hline \multicolumn{5}{|l|}{} \\
\hline 3 & 2 & CL368 & Presolder & 2.92 \\
\hline 3 & 5 & CL349 & Presolder & 4.87 \\
\hline 3 & 17 & RL462 & Presolder & -0.16 \\
\hline \multicolumn{5}{|l|}{} \\
\hline 4 & 5 & RL359 & Presolder & 0.63 \\
\hline 4 & 7 & RL426 & Presolder & -0.7 \\
\hline 4 & 10 & RL369 & Presolder & -0.33 \\
\hline
\end{tabular}

Table 6. Inspection of RF Transistors Using SMTGauge

\begin{tabular}{|c|c|c|c|c|}
\hline Position Number & Circuit Position & $\begin{array}{c}\text { Discrepancy in X } \\
\text { (mils) }\end{array}$ & $\begin{array}{c}\text { Discrepancy in Y } \\
\text { (mils) }\end{array}$ & $\begin{array}{c}\text { Discrepancy of } \\
\text { Theta Angle } \\
\text { (degrees) }\end{array}$ \\
\hline 1 & QL302 & -2 & 1 & 0.86 \\
\hline 2 & QL311 & -3 & 0 & -0.57 \\
\hline 3 & QL304 & -2 & 0 & \\
\hline 4 & QL301 & -3 & -1 & \\
\hline 5 & QL310 & -2 & -1 & 0.58 \\
\hline 6 & QL309 & -1 & 1 & 0.73 \\
\hline 7 & QL305 & -3 & 0 & 0.69 \\
\hline 8 & QL313 & -2 & -2 & \\
\hline 9 & QL314 & -2 & 0 & \\
\hline
\end{tabular}

Difficulties imaging plastic molded chip inductors -- The laser light is absorbed by the material that makes up the body of the inductors. These components could not be imaged by the system.

Difficulties in edge determination of RF Transistors -- The RF transistors have a square ceramic body with a round lid. The round edge of the lid created a great deal of difficulty for the system to determine the edges of the components. The XYGauge and XYTGauge were not able to reliably determine the edges of a transistor. Although the SMTGauge was developed for use with chip components, a template was developed for the RF transistor 
using this algorithm. It was able to reliably determine the edges of the transistor since it finds the contour of all four edges within one large inspection box and averages out the semicircular shape of the lid from each edge.

Difficulties in edge determination of chip resistors with "fat" solder terminations - The system had difficulty determining the edges of chip resistors that did not have a clearly defined edge due to a gradually sloping solder joint all the way up the side of the termination. The amount of solder on both of the postsoldered boards created this solder joint geometry for most all of the chip resistors. The amount of solder on these terminations was just within the maximum allowed by the A issue of the SS394234 solder specification and represented the worst case for detection by the system.

The lack of a clearly defined edge causes the system to either not detect a component edge or detect the edge incorrectly, depending on the setting of the parameter that defines the sensitivity of the system. This parameter is defined as the edge strength in the template for the component. The number chosen for the edge strength describes how suddenly a shift in height needs to occur before the system recognizes it as the edge of a component. If the edge strength is set too low, the system will falsely detect edges that do not exist. An edge strength that is too high will prevent the system from recognizing the component edge. The edge strength for the evaluation was set as low as possible without allowing the system to detect false edges. At this setting, 23\% (31 of 132) of the chip resistors on the second postsoldered circuit contained edges that were not detected by the system. To effectively use the system in the postsoldered case, the solder fillet geometry of the chip resistors needed to be farther below the top edge of the component.

System accuracy in inspection of type 550 chip resistors in both the presoldered and postsoldered cases-- To determine how well the system was able to determine the center of the components by finding their edges, an evaluation was made of some of the data in Tables 1 through 4. The data for all 550 resistors that do not have a comment in the "observations" column were evaluated. The 550 resistors were chosen because they were the most common component used, one of the most difficult chip components for edge determination, and the most sensitive to misalignment. The 550 resistor data that contain comments in the "observations" column were so far misaligned that they did not lie within the normal envelope of the gauging algorithm or they contained so much excess solder (in the postsoldered case) that the system could not find the component edges.

To learn how well the system was able to determine the component rotation, an evaluation was made of the data in Table 5. The component position and rotation data for the presoldered and postsoldered cases were evaluated separately, and the variation between them was found to be insignificant. The data for both cases were then combined, and these results are given in Table 7. The data was analyzed using Microsoft Excel version 5.0. The standard deviation calculation was of a sample using the "non-biased" or "n-1" method by using the STDEV function in Excel. 
Table 7. Evaluation of Data From Tables 1 Through 6

\begin{tabular}{|c|c|c|c|c|c|c|}
\hline & $\begin{array}{c}\text { 550 Resistor } \\
\text { X Direction } \\
\text { Error (mils) }\end{array}$ & $\begin{array}{c}\text { 550 Resistor } \\
\text { Y Direction } \\
\text { Error (mils) }\end{array}$ & $\begin{array}{c}\text { Components } \\
\text { Rotation } \\
\text { Error } \\
\text { (degrees) }\end{array}$ & $\begin{array}{c}\text { RF Transistor } \\
\text { X Direction } \\
\text { Error (mils) }\end{array}$ & $\begin{array}{c}\text { RF Transistor } \\
\text { Y Direction } \\
\text { Error (mils) }\end{array}$ & $\begin{array}{c}\text { RF Transistor } \\
\text { Theta Error } \\
\text { (degrees) }\end{array}$ \\
\hline Average & 0.85 & -1.15 & -1.54 & -2.22 & -0.22 & 0.46 \\
\hline Sigma & 1.93 & 2.03 & 3.92 & 0.67 & 0.97 & 0.58 \\
\hline $3 \times$ Sigma & 5.80 & 6.10 & 11.74 & 2.00 & 2.92 & 1.75 \\
\hline
\end{tabular}

System accuracy in inspection of RF transistors using the SMTGauge template -- To determine how well the system was able to find the center and rotational angle of the RF transistors using the SMGauge algorithm, an evaluation was made of the data in

Table 6. The results are given in Table 7. The data was analyzed as done previously using Microsoft Excel version 5.0. The standard deviation calculation was of a sample using the "non-biased" or "n-1" method by using the STDEV function in Excel.

After performing the evaluation, it was determined that the system was more accurate at finding the center of the component than a typical visual inspection without the use of a measuring microscope and that the system was very unlikely to allow misaligned components to pass as good, while the difficulties with "fat" solder terminations cause a fair number of false rejects per inspection. This results in a system that narrows down the number of components that need to be evaluated but does not replace human visual inspection. Due to the limitations of the system, additional requirements of total visual inspection of the circuit for proper solder joints (regardless of the use of the system), reduced workload, and reduced departmental workspace, the system was excessed and never brought into production.

Soon after this project was initialized, a newer system made by Robotic Vision Systems Inc. was purchased. This system (model HR-2000) uses the same laser imaging technology as the SVS system. This system has the potential of being much more useful due to its ability to perform both component misalignment inspection along with the inspection of solder joints. An evaluation was performed on this system under another FM\&T project (High Resolution ThreeDimensional Solder Joint Measurement System Evaluation [Final Report], by M. A. Trent, KCP-613-4939, December 1992, available from NTIS). This project focused on solder joint inspection of through hole components, but the system was designed for use with surface mount assemblies. Future work is needed to evaluate this system for use on surface mount assemblies. 


\section{ACCOMPLISHMENTS}

The automated visual inspection system was evaluated and found to be accurate at finding the center of components with a good clean edge; it was very unlikely to allow misaligned components to pass as good. The limitations of the system were due to inconsistency in the solder joints of components on the assembly and its inability to accomplish all of the visual inspection operations normally performed. Due to the limitations of the system, additional requirements of total visual inspection of the circuit for proper solder joints (regardless of the use of the system), reduced workload, and reduced departmental workspace, the system was excessed and never brought into production.

Soon after this project was initialized, a newer system made by Robotic Vision Systems Inc. was purchased. This system (model HR-2000) uses the same laser imaging technology as the SVS system and has the potential of being much more useful due to its ability to perform both component misalignment inspection along with the inspection of solder joints. An evaluation was performed on this system. This project foçused on solder joint inspection of through hole components, but the system was designed for use with surface mount assemblies. Future work is needed to evaluate this system for use on surface mount assemblies. 